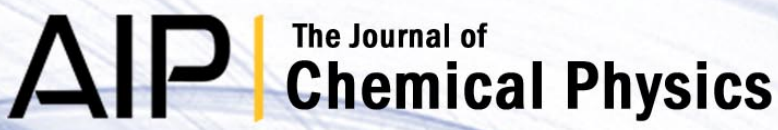

Molecular dynamics simulation of the spherical electrical double layer of a soft nanoparticle: Effect of the surface charge and counterion valence

Miroslava Nedyalkova, Sergio Madurga, Stoyan Pisov, Isabel Pastor, Eudald Vilaseca et al.

Citation: J. Chem. Phys. 137, 174701 (2012); doi: 10.1063/1.4762830

View online: http://dx.doi.org/10.1063/1.4762830

View Table of Contents: http://jcp.aip.org/resource/1/JCPSA6/v137/i17

Published by the American Institute of Physics.

Additional information on J. Chem. Phys.

Journal Homepage: http://jcp.aip.org/

Journal Information: http://jcp.aip.org/about/about_the_journal

Top downloads: http://jcp.aip.org/features/most_downloaded

Information for Authors: http://jcp.aip.org/authors

\section{ADVERTISEMENT}

\section{ACCELERATE COMPUTATIONAL CHEMISTRY BY 5X. TRY IT ON A FREE, REMOTELY-HOSTED CLUSTER. \\ RVIDIA.}




\title{
Molecular dynamics simulation of the spherical electrical double layer of a soft nanoparticle: Effect of the surface charge and counterion valence
}

\author{
Miroslava Nedyalkova, ${ }^{1}$ Sergio Madurga, ${ }^{2, a)}$ Stoyan Pisov, ${ }^{3}$ Isabel Pastor, ${ }^{2}$ \\ Eudald Vilaseca, ${ }^{2}$ and Francesc Mas ${ }^{2}$ \\ ${ }^{1}$ Faculty of Chemistry, University of Sofia, 1164 Sofia, Bulgaria \\ ${ }^{2}$ Physical Chemistry Department and Research Institute of Theoretical and Computational Chemistry \\ (IQTCUB) of the University of Barcelona (UB), 08028 Barcelona, Catalonia, Spain \\ ${ }^{3}$ Faculty of Physics, University of Sofia, 1164 Sofia, Bulgaria
}

(Received 26 July 2012; accepted 24 September 2012; published online 1 November 2012)

\begin{abstract}
Molecular dynamics simulations were performed to study the ion and water distribution around a spherical charged nanoparticle. A soft nanoparticle model was designed using a set of hydrophobic interaction sites distributed in six concentric spherical layers. In order to simulate the effect of charged functionalyzed groups on the nanoparticle surface, a set of charged sites were distributed in the outer layer. Four charged nanoparticle models, from a surface charge value of $-0.035 \mathrm{C} \mathrm{m}^{-2}$ to $-0.28 \mathrm{C} \mathrm{m}^{-2}$, were studied in $\mathrm{NaCl}$ and $\mathrm{CaCl}_{2}$ salt solutions at $1 \mathrm{M}$ and $0.1 \mathrm{M}$ concentrations to evaluate the effect of the surface charge, counterion valence, and concentration of added salt. We obtain that $\mathrm{Na}^{+}$and $\mathrm{Ca}^{2}+$ ions enter inside the soft nanoparticle. Monovalent ions are more accumulated inside the nanoparticle surface, whereas divalent ions are more accumulated just in the plane of the nanoparticle surface sites. The increasing of the the salt concentration has little effect on the internalization of counterions, but significantly reduces the number of water molecules that enter inside the nanoparticle. The manner of distributing the surface charge in the nanoparticle (uniformly over all surface sites or discretely over a limited set of randomly selected sites) considerably affects the distribution of counterions in the proximities of the nanoparticle surface. (C) 2012 American Institute of Physics. [http://dx.doi.org/10.1063/1.4762830]
\end{abstract}

\section{INTRODUCTION}

Nanoparticles are an object of intense scientific investigation because of their potential application in a variety of fields, such as medicine, cosmetics, toxicology, food, and enviroment sciences. ${ }^{1-8}$ The understanding of the properties and processes occurring in solutions of charged nanoparticles requires the determination of the structure of the interfacial region between their charged surface and the diffuse layer of coions and counterions, commonly referred as electrical double layer (EDL). Theoretical approaches, based on Poisson Boltzmann or integral equation theories, and computer simulations, such as Monte Carlo and molecular dynamics, have been done to study the EDL in different geometries. ${ }^{9-11}$

Computer simulations of spherical nanoparticles have been carried out at different levels of approximation depending on the treatment of water, ions, and colloidal particles. Initially, Monte Carlo simulations of spherical nanoparticles were performed in the context of the primitive model, in which ions are treated as charged hard spheres and solvent is considered as a continuous medium. When counterions and coions have the same size, this model is referred to as a restricted primitive model. These approaches have been employed to identify the range of validity of analytical expressions based on Poisson-Boltzmann (PB), integral equations or density functional theories. ${ }^{12-15}$ Polyelectrolyte adsorption

a) Electronic mail: s.madurga@ub.edu. URL: www.ub.edu/biophyschem. on charged nanoparticles was also studied at the primitive level. ${ }^{16}$ The limitations of the primitive model to properly describe the EDL of a spherical nanoparticle were identified by Monte Carlo simulations in which water molecules were modelled as neutral hard disk spheres. ${ }^{17,18}$ These authors concluded that the explicit consideration of water molecules affects the layering and charge inversion properties. It should be pointed out that in all these previous studies, the nanoparticle was modelled as a hard sphere being impenetrable to other particles of the system.

On the other hand, Rakitin and Pack studied the ion distribution around micelles with different approaches; first, using MC simulations within a Primitive Mode ${ }^{19}$ and comparing the results with the $\mathrm{PB}$ model, then using $\mathrm{MD}$ simulations with explicit water molecules and different monovalent cations. ${ }^{20}$ They showed that there is an agreement between MC and MD results. The charged head group-ion distance increases in the same sense of the ionic radius. Finally, they concluded that the loss of waters of hydration from the simple electrolyte ions imply that the bare ion radii are a better measure of the ion size in the vicinity of the micelles.

Recently, Semashko et al. simulated the EDL of a spherical micelle using different models for both the colloid and water molecules. ${ }^{21}$ They concluded that explicit molecules are required for the correct description of the EDL properties. A permeable spherical micelle was simulated in the presence of monovalent ions by Brodskaya to study the role of water in the formation of the EDL.22 
In this work, we study the EDL of a soft model of a hydrophobic nanoparticle functionalized with polar groups being permeable to ions and water molecules. In a previous work, we studied the EDL around a functionalyzed latex nanoparticle in the context of the primitive model. ${ }^{10,11,23}$ Now, the effect of considering explicit water molecules and of using a soft model for the nanoparticle is analyzed by means of molecular dynamics simulations. A series of simulations covering different conditions was carried out to evaluate the effect of the surface charge, valence of counterion, and concentration of added salt.

\section{COMPUTATIONAL DETAILS}

In order to study the EDL of a typical hydrophobic nanoparticle functionalyzed with groups that can be charged, for example modifying the $\mathrm{pH}$ conditions, a soft nanoparticle model having a different number of surface charges was designed (Figure 1). The nanoparticle is considered to be formed by a set of interaction sites distributed along six concentric spherical layers. The arrangement of nanoparticle sites in spherical geometry allows us to easily analyse the behaviour of water and ions in the proximities of the nanoparticle surface by means of radial distribution functions. A program was developed to generate the coordinates of the sites in the different layers. An iterative procedure is used to add progressively new sites at random positions of a surface sphere if they do not overlap with previous sites in the same layer. A hard sphere radius of $0.25 \mathrm{~nm}$ is assigned to the nanoparticle sites. We generated six concentric layers having a radius of $0.5,1.0,1.5,2.5$, and $3.0 \mathrm{~nm}$. The total number of sites in the nanoparticle are 942 and those that belong to the outer layer are 370 . The hard sphere radius is only used in the procedure to build up the nanoparticle. During the molecular dynamics simulations, the interactions of these sites with the ionic solution were calculated using the values of the Lennard-Jones (LJ) parameters corresponding to methane molecules in the Gromacs ffG43a1 force-field $(\sigma=0.37 \mathrm{~nm}$, $\epsilon=1.264 \mathrm{~kJ})$. No charge was assigned to the sites that belong to the inner five layers, modelling a completely hydrophobic core of the nanoparticle. In the outer layer (6th layer), some sites were assigned a negative charge according to the total charge of the nanoparticle. We think that the selected parameters are appropriated because, as expected for a completely hydrophobic nanoparticle, in its non-charged state, water molecules are not able to enter inside the particle during a 5 ns molecular dynamics calculation.

We have generated four nanoparticle charged models randomly distributing a negative charge over $25,50,100$, or 200 sites in the outer layer (or surface sites). Consequently, the surface charge densities of these four nanoparticles correspond to $-0.035,-0.07,-0.14$, and $-0.28 \mathrm{C} \mathrm{m}^{-2}$. The spherical model of the charged nanoparticle was placed in the center of a cubic box of dimensions $16 \times 16 \times 16 \mathrm{~nm}^{3}$ filled with water molecules and salt ions at different concentrations. Periodic boundary conditions were used, being all the system replicated in $x, y$, and $z$ directions. The molecular dynamics simulations were performed with the Gromacs package, ${ }^{24-27}$ version 4.0, using a time step of $2 \mathrm{fs}$. The LJ
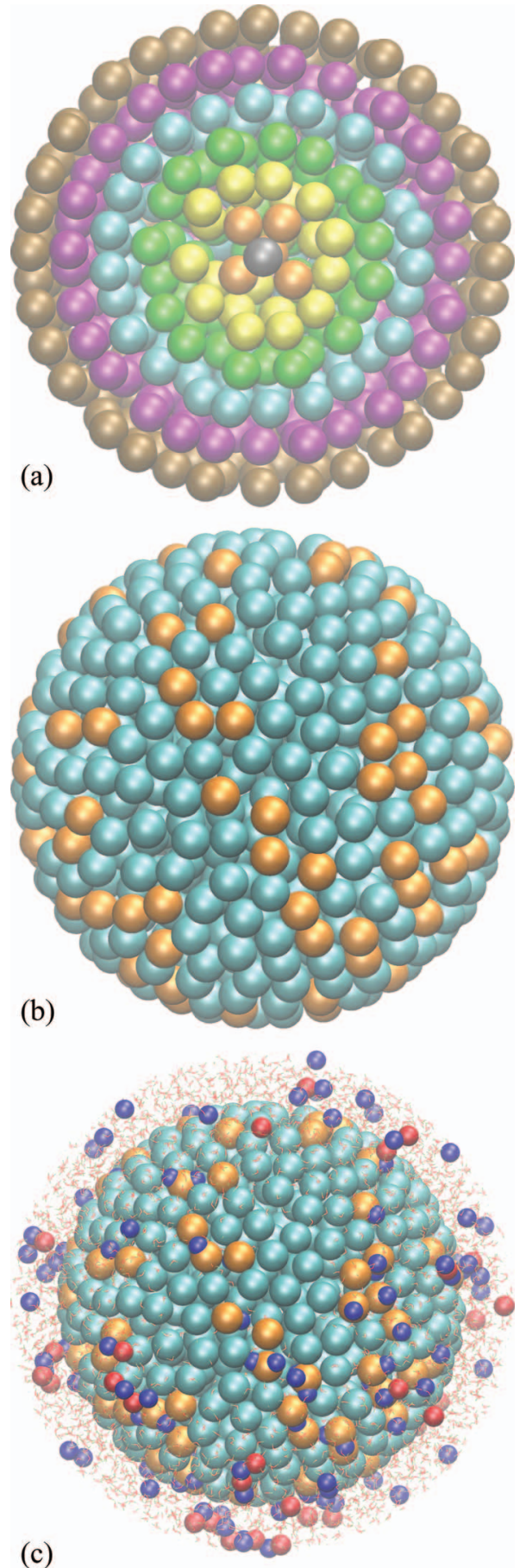

FIG. 1. A cut of the nanoparticle showing the interaction sites distributed in six different layers. Each layer is shown by a different color (a). The $-100 \mathrm{e}$ $\left(-0.14 \mathrm{C} \mathrm{m}^{-2}\right)$ charged nanoparticle indicating the surface charged sites in orange (b). Snapshot of a simulation of the $-100 \mathrm{e}$ charged nanoparticle in 1 $\mathrm{M} \mathrm{NaCl}$ solution. Only water molecules, $\mathrm{Na}^{+}$ions (in blue), and $\mathrm{Cl}^{-}$ions (in red) close to $1.0 \mathrm{~nm}$ from the nanoparticle surface are displayed (c).

forces were calculated with a cutoff of $1.4 \mathrm{~nm}$. The electrostatic forces were calculated by the Particle-Mesh Ewald method $^{28}$ using a real-space cutoff of $1.4 \mathrm{~nm}$ with a grid spacing of $0.12 \mathrm{~nm}$. The system was simulated at constant volume and at constant temperature of $300 \mathrm{~K}$, using the velocity rescaling thermostat. ${ }^{29}$ In the molecular dynamics calculations, the nanoparticle sites were fixed with a force constant of $10000 \mathrm{~kJ} \mathrm{~mol}^{-1} \mathrm{~nm}^{-1}$. Bond distances and angle of more 
than 123000 Simple Point Charge (SPC) water molecules were constrained using the SETTLE algorithm. ${ }^{30}$ For each of the four charged models of the nanoparticle, different molecular dynamics calculations were carried out at $0.1 \mathrm{M}$ and $1 \mathrm{M}$ concentrations of $\mathrm{NaCl}$ or $\mathrm{CaCl}_{2}$. In all cases, at least $10 \mathrm{~ns}$ were performed using the first $5 \mathrm{~ns}$ as an equilibration period. Calculations were performed with the MareNostrum supercomputer at the Barcelona Supercomputer Center and in the IQTCUB cluster at the Barcelona University.

\section{RESULTS AND DISCUSSION}

\section{A. Effect of monovalent counterions}

The local density of $\mathrm{Na}^{+}$ions in function of the distance to the center of the nanoparticle is shown in Figure 2(a) for $0.1 \mathrm{M} \mathrm{NaCl}$ solution. As expected, the density of $\mathrm{Na}^{+}$in the proximities of the surface $(3 \mathrm{~nm})$ is lower for the lower charged nanoparticle. This density increases with the number of surface charged sites because more $\mathrm{Na}^{+}$ions are required to compensate the surface charge.

In all nanoparticle models, the density profile of $\mathrm{Na}^{+}$ shows a set of peaks in the range of 2.75 to $3.25 \mathrm{~nm}$. Those that are located at a distance less than $3 \mathrm{~nm}$ correspond to
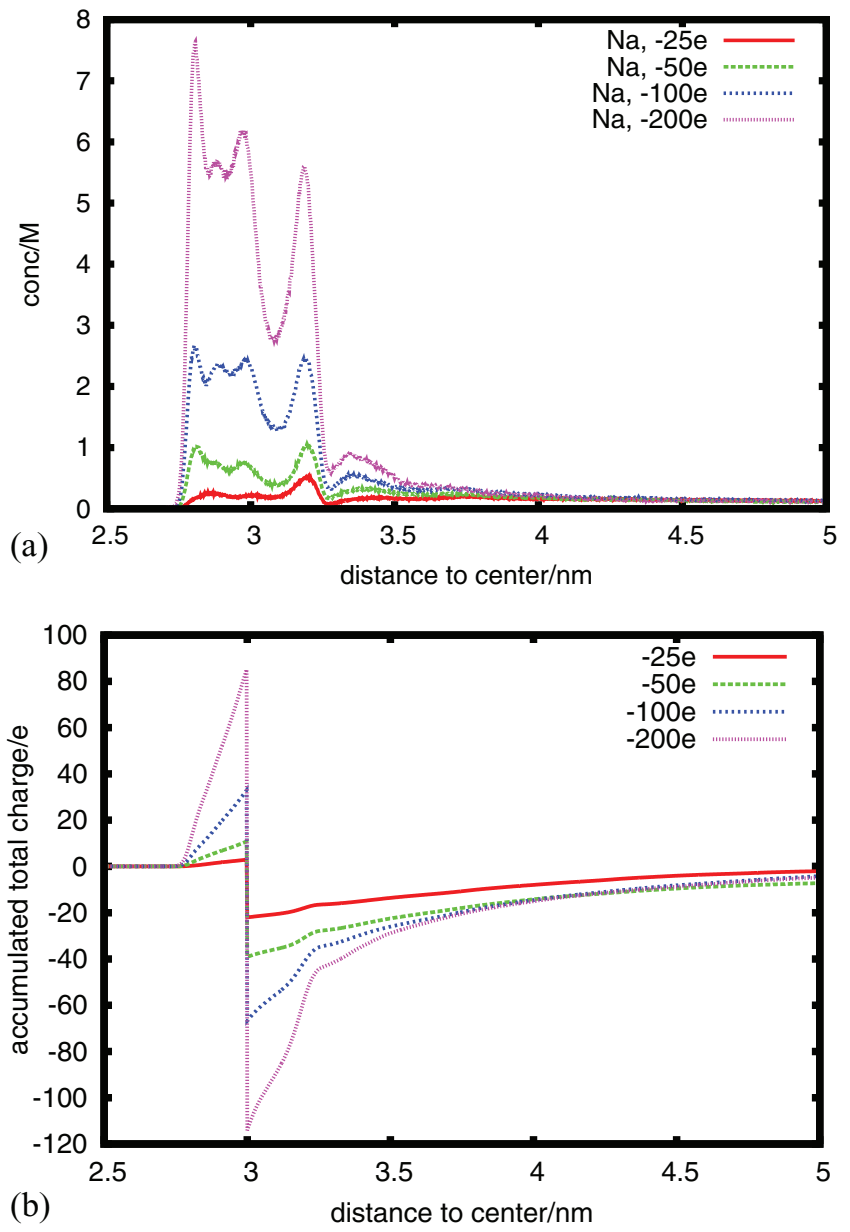

FIG. 2. Density profiles of $\mathrm{Na}^{+}$ions (a) and accumulated charge profiles (b) with respect to the center of the $-25 \mathrm{e}\left(-0.035 \mathrm{C} \mathrm{m}^{-2}\right),-50 \mathrm{e}\left(-0.07 \mathrm{C} \mathrm{m}^{-2}\right)$, $-100 \mathrm{e}\left(-0.14 \mathrm{C} \mathrm{m}^{-2}\right)$, and $-200 \mathrm{e}\left(-0.28 \mathrm{C} \mathrm{m}^{-2}\right)$ charged nanoparticles for a $0.1 \mathrm{M} \mathrm{NaCl}$ solution.
TABLE I. Integration number of $\mathrm{Na}$ ions and oxygen atoms of water molecules from the center to the nanoparticle to 3.0 and/or $3.25 \mathrm{~nm}$ in simulations of $\mathrm{NaCl}$ solutions.

\begin{tabular}{lrrrr}
\hline \hline System & $-25 \mathrm{e}$ & $-50 \mathrm{e}$ & $-100 \mathrm{e}$ & $-200 \mathrm{e}$ \\
\hline $\mathrm{Na}^{+}, 0.1 \mathrm{M}$ at $3.0 \mathrm{~nm}$ & 3.0 & 10.9 & 33.3 & 85.9 \\
$\mathrm{Na}^{+}, 1 \mathrm{M}$ at $3.0 \mathrm{~nm}$ & 3.0 & 11.5 & 33.5 & 83.9 \\
$\mathrm{Na}^{+}, 0.1 \mathrm{M}$ at $3.25 \mathrm{~nm}$ & 8.5 & 22.2 & 65.2 & 155.6 \\
$\mathrm{Na}^{+}, 1 \mathrm{M}$ at $3.25 \mathrm{~nm}$ & 15.6 & 36.1 & 75.4 & 190.9 \\
$\mathrm{O}$ water, $0.1 \mathrm{M}$ at $3.0 \mathrm{~nm}$ & 94.7 & 192.1 & 400.8 & 799.5 \\
$\mathrm{O}$ water, $1 \mathrm{M}$ at $3.0 \mathrm{~nm}$ & 80.8 & 162.6 & 352.9 & 727.6 \\
\hline \hline
\end{tabular}

$\mathrm{Na}^{+}$ions situated between the last two spherical layers of the nanoparticle. Those that are located at a distance of $3.0 \mathrm{~nm}$ correspond to ions that are situated in the surface of the outer layer among several surface sites, and those that are locate at a distance greater than $3.0 \mathrm{~nm}$ correspond to $\mathrm{Na}^{+}$ions situated outside the nanoparticle. The height of the three peaks reveals that in all cases, there is a significant ion population in these three zones. Thus, we obtain that $\mathrm{Na}^{+}$ions are able to enter inside the nanoparticle because a non-null density of $\mathrm{Na}^{+}$ions is obtained below $3.0 \mathrm{~nm}$. To interpret the shape of these collection of peaks, we have to bear in mind that below $3.0 \mathrm{~nm}$, there is an important excluded volume effect produced by the nanoparticle sites. Ions are obligated to occupy favourable electrostatic positions that are not occupied by the sites of the nanoparticle. These positions correspond to the series of peaks observed in Figure 2. In addition, it can be seen that the amount of counterions able to enter inside the nanoparticle (below $3.0 \mathrm{~nm}$ ) and those close to the surface (below $3.25 \mathrm{~nm}$ ) increase with the increment of the surface charge (Table I). For example, at $0.1 \mathrm{M} \mathrm{NaCl}$ concentration, we have only $3 \mathrm{Na}^{+}$ions inside the $-25 \mathrm{e}$ charged nanoparticle (below a distance of $3.0 \mathrm{~nm}$ ), and $86 \mathrm{Na}^{+}$inside the $-200 \mathrm{e}$ $\left(-0.28 \mathrm{C} \mathrm{m}^{-2}\right)$ charged nanoparticle. In contrast, $\mathrm{Cl}$ - ions do not enter inside the nanoparticle because of the electrostatic repulsion with the negatively charged surface sites. A nonnull density of $\mathrm{Cl}$ - ions starts at $0.2-0.3 \mathrm{~nm}$ from the surface and increases progressively at longer distances to achieve the bulk value (results not shown).

In Figure 2(b), it can be seen the charge accumulation from the center of the nanoparticle to different radial values. This is calculated using the $\int_{0}^{r} \sum_{i} n_{i}(r) z_{i} d r^{\prime}$ expression, where $z_{i}$ is the valence and $n_{i}(r)$ is the number of particles of type $i$ at a distance $r$ from the nanoparticle center. The charge integration has been computed for nanoparticles with a charge of $-25 \mathrm{e},-50 \mathrm{e},-100 \mathrm{e}$, and $-200 \mathrm{e}$ (or equivalently to $-0.035,-0.07,-0.14$, and $-0.28 \mathrm{C} \mathrm{m}^{-2}$ ) immersed in a $0.1 \mathrm{M} \mathrm{NaCl}$ solution. In all cases, the profiles start from zero because no charge is located below the $2.5 \mathrm{~nm}$ layer of the nanoparticle. Then, an increase of the accumulated charge is observed in all the profiles because some $\mathrm{Na}^{+}$ions enter inside the nanoparticle (below $3.0 \mathrm{~nm}$ ). The charged sites of the nanoparticle are situated in the outer layer, at $3.0 \mathrm{~nm}$ from its center. Thus, at this distance, the accumulated charge sums the $-25 \mathrm{e},-50 \mathrm{e},-100 \mathrm{e}$, or $-200 \mathrm{e}$ charges for the four nanoparticle models and the profiles show a drop. For distances longer than $3 \mathrm{~nm}$, all profiles show a monotonic increase going to 
the zero value indicating that the system is neutralized. In all cases, no overcharging phenomena is observed because there is no maximum in the profiles of the accumulated charge beyond $3.0 \mathrm{~nm}$.

To study the effect of the bulk concentration of the $\mathrm{NaCl}$ salt on the electrostatic properties of the system, we performed a new series of molecular dynamics calculations considering now that each nanoparticles is immersed in a $1 \mathrm{M}$ $\mathrm{NaCl}$ solution. The obtained profiles for the local density of $\mathrm{Na}^{+}$at $1 \mathrm{M}$ concentration (Figure 3(a)) show an accumulation of counterions in the same region, from 2.75 to $3.25 \mathrm{~nm}$, as in the case of $0.1 \mathrm{M}$ (Figure 2(a)). For both concentrations, we obtain a significant counterion population inside and outside the nanoparticle for all charged models. However, at $1 \mathrm{M}$ concentration, the peak around 3.25 is higher for all nanoparticle models. Thus, the increase of bulk concentration makes that more quantity of counterions appears in the interface. The accumulated values of $\mathrm{Na}^{+}$ions until a distance of $3.0 \mathrm{~nm}$ and until $3.25 \mathrm{~nm}$ from the center of the nanoparticle can be seen in Table I. The integration numbers of $\mathrm{Na}^{+}$ions until a distance of $3.0 \mathrm{~nm}$ are similar for both concentrations. However, the integration until $3.25 \mathrm{~nm}$ gives greatest values for the cases with $1 \mathrm{M} \mathrm{NaCl}$ concentration. Thus, the effect of
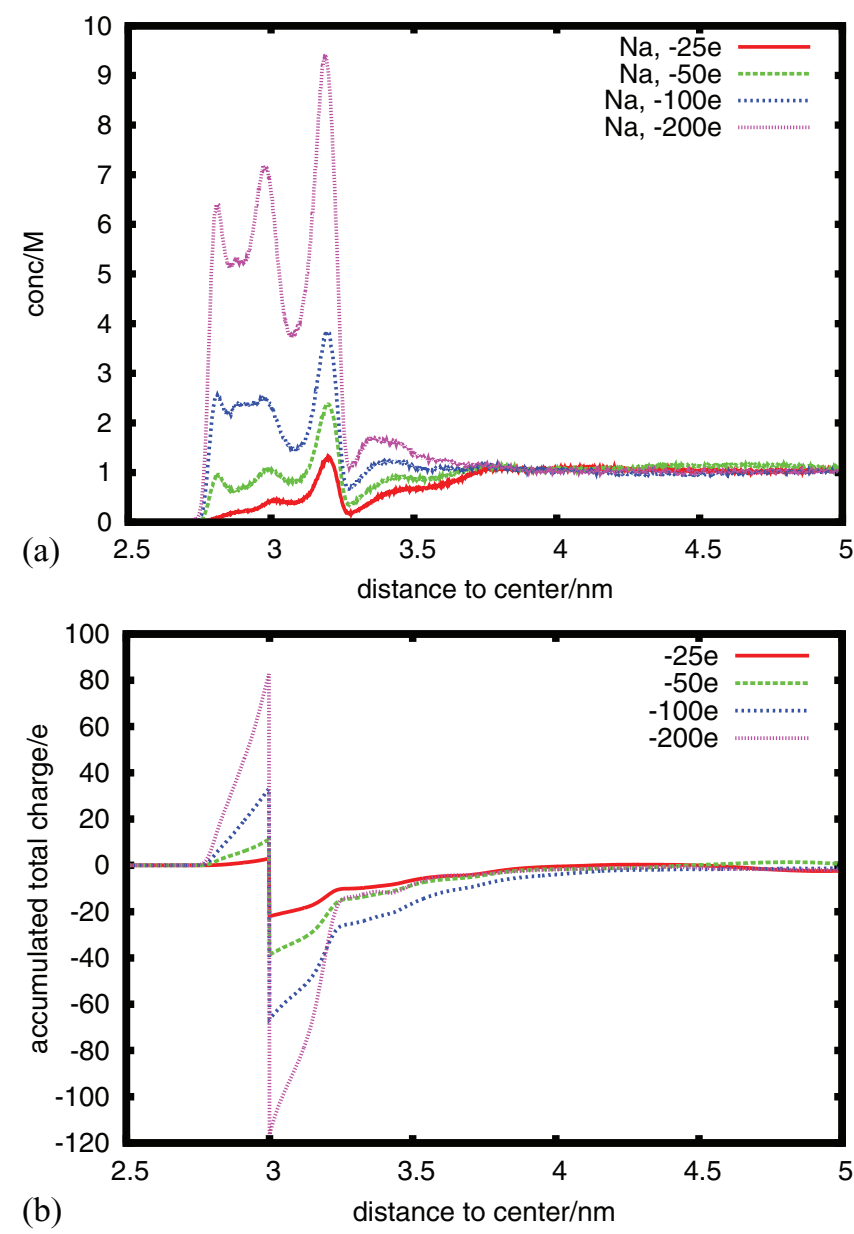

FIG. 3. Density profiles of $\mathrm{Na}^{+}$ions (a) and accumulated charge profiles (b) with respect to the center of the $-25 \mathrm{e}\left(-0.035 \mathrm{C} \mathrm{m}^{-2}\right),-50 \mathrm{e}\left(-0.07 \mathrm{C} \mathrm{m}^{-2}\right)$, $-100 \mathrm{e}\left(-0.14 \mathrm{C} \mathrm{m}^{-2}\right)$, and $-200 \mathrm{e}\left(-0.28 \mathrm{C} \mathrm{m}^{-2}\right)$ charged nanoparticles for a $1 \mathrm{M} \mathrm{NaCl}$ solution. increasing the bulk salt concentration is an increase of the quantity of counterions in the external part of the surface. We also have to take into account that this greatest accumulation of counterions is accompanied with a greatest accumulation of coions. Consequently, the obtained profiles for the accumulated charge at $1 \mathrm{M} \mathrm{NaCl}$ concentration (Figure 3(b)) are similar to those obtained at $0.1 \mathrm{M} \mathrm{NaCl}$ concentration in the proximity of the nanoparticle surface with the exception of the $-200 \mathrm{e}\left(-0.28 \mathrm{C} \mathrm{m}^{-2}\right)$ charged model. This different behaviour is explained because only in this case the density of $\mathrm{Cl}^{-}$ions has a maximum around $3.4 \mathrm{~nm}$ (results not shown). As expected, in all cases we observed that the neutralization of the system for $1 \mathrm{M} \mathrm{NaCl}$ is reached at closer distances than for $0.1 \mathrm{M} \mathrm{NaCl}$. Because there is no maximum with the positive value of the accumulated charge profiles after $3.0 \mathrm{~nm}$, no overcharging is produced at $1 \mathrm{M} \mathrm{NaCl}$.

Figure 4 shows the distribution of water molecules with respect to the distance to the center of the nanoparticles for both $0.1 \mathrm{M}$ and $1 \mathrm{M} \mathrm{NaCl}$ concentrations. It can be seen that water molecules can internalize into the nanoparticle in a region between the last two layers of sites. More water molecules are internalized as the charge of the nanoparticle increases. This behaviour is explained because water
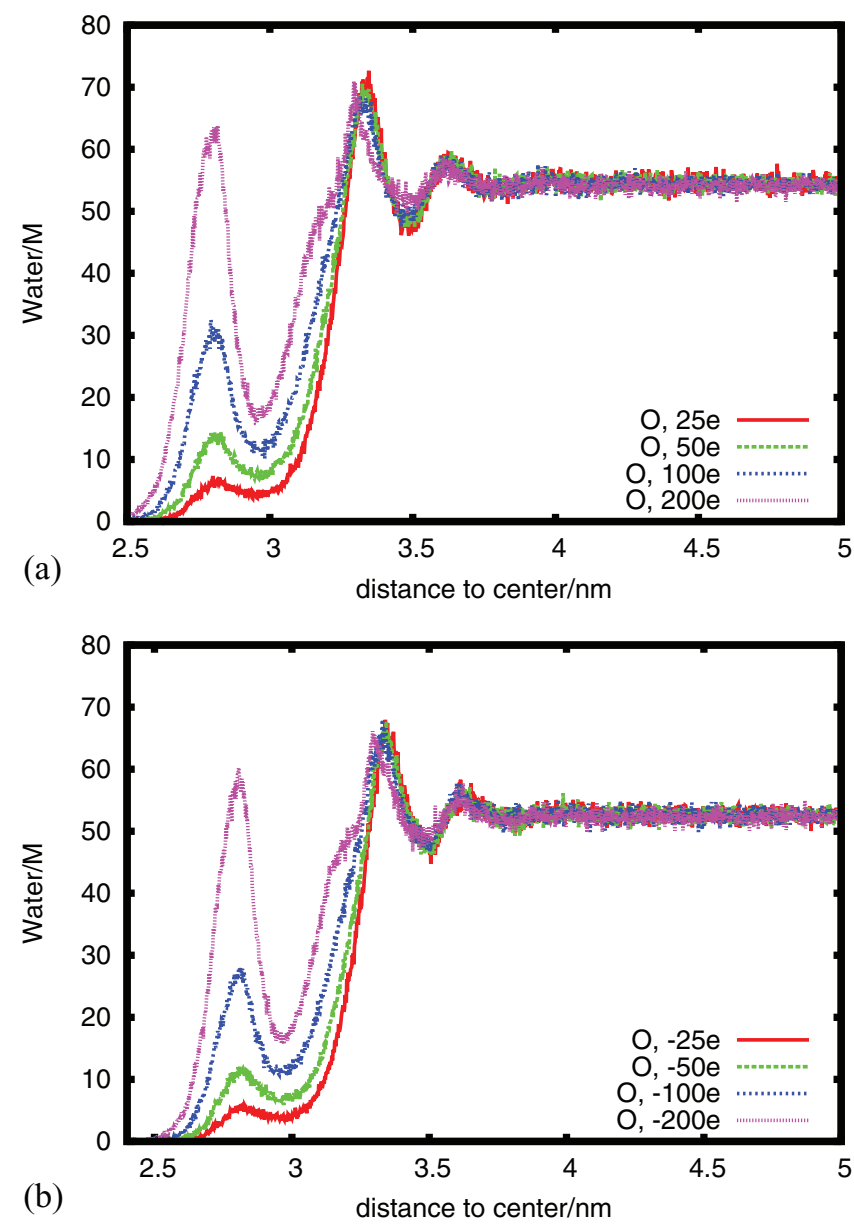

FIG. 4. Density of water molecules with respect to the distance to the center of the $-25 \mathrm{e}\left(-0.035 \mathrm{C} \mathrm{m}^{-2}\right),-50 \mathrm{e}\left(-0.07 \mathrm{C} \mathrm{m}^{-2}\right),-100 \mathrm{e}\left(-0.14 \mathrm{C} \mathrm{m}^{-2}\right)$, and $-200 \mathrm{e}\left(-0.28 \mathrm{C} \mathrm{m}^{-2}\right)$ charged nanoparticles for (a) $0.1 \mathrm{M} \mathrm{NaCl}$ and (b) $1 \mathrm{M} \mathrm{NaCl}$ solutions. 
molecules can establish hydrogen bonds with the negatively charged sites of the surface, and with the counterions being positively charged. In can be seen that for the same nanoparticle charge, more water molecules can enter inside the nanoparticle for the case of $0.1 \mathrm{M}$ than with respect to the $1 \mathrm{M} \mathrm{NaCl}$ (Table I). Thus, at a higher concentration of $\mathrm{NaCl}$, fewer water molecules appear inside the charged nanoparticle. To sum up, we obtain that the increase of bulk salt concentration does not modify significantly the permeability of the nanoparticle to the penetration of counterions, however the penetration of solvent molecules diminishes.

\section{B. Effect of divalent counterions}

The local density of $\mathrm{Ca}^{2+}$ ions in a function of the distance to the center of the nanoparticle is shown in Figure 5(a) for a $0.1 \mathrm{M} \mathrm{CaCl}_{2}$ solution. Important differences can be observed with respect to the corresponding profiles for $\mathrm{NaCl}$ solution at the same concentration (Figure 2(a)). A marked maximum in the density of $\mathrm{Ca}^{2}+$ ions is located just at the distance of the surface sites in the outer layer, at $3.0 \mathrm{~nm}$. Thus, the general tendency is that the divalent ions are less internalized than the monovalent ions remaining at the same dis-
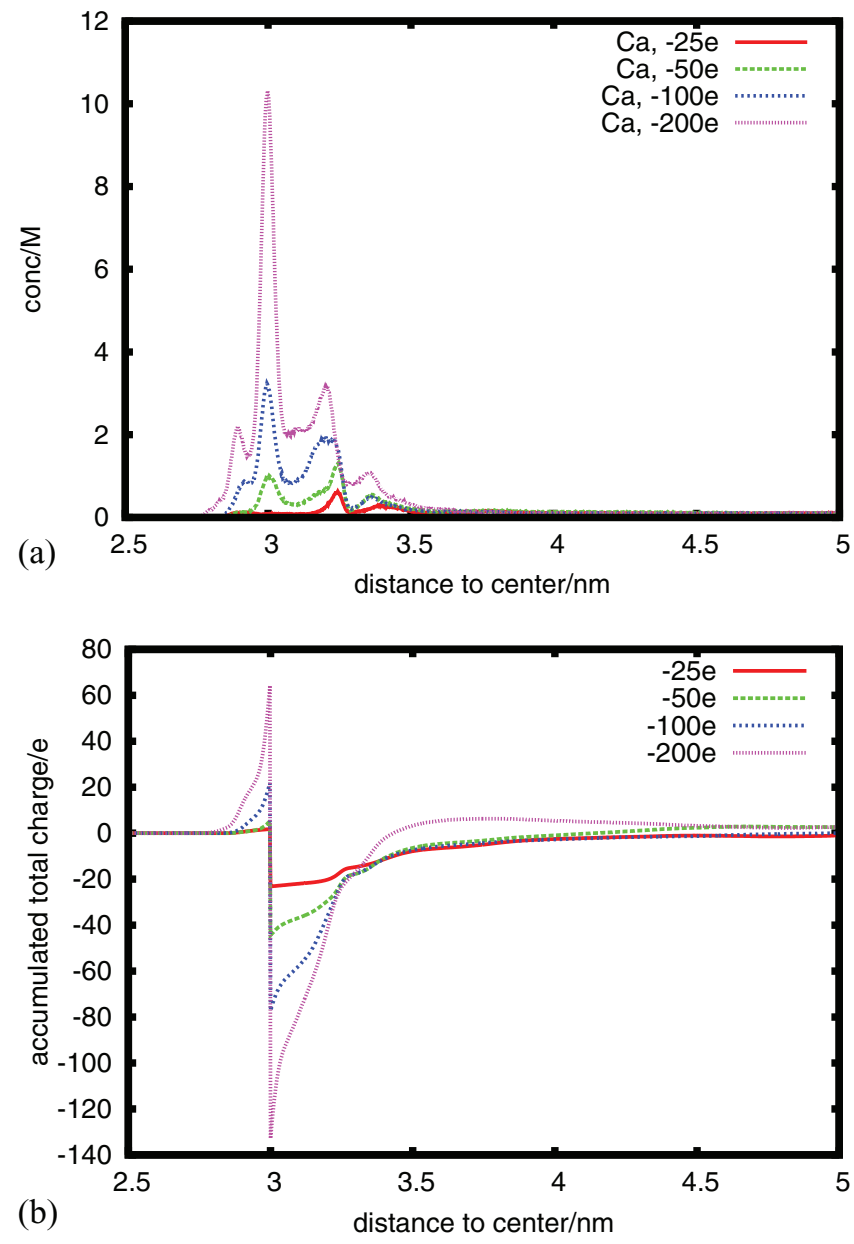

FIG. 5. Density profiles of $\mathrm{Ca}^{2}+$ ions (a) and accumulated charge profiles (b) with respect to the center of the $-25 \mathrm{e}\left(-0.035 \mathrm{C} \mathrm{m}^{-2}\right),-50 \mathrm{e}\left(-0.07 \mathrm{C} \mathrm{m}^{-2}\right)$, $-100 \mathrm{e}\left(-0.14 \mathrm{C} \mathrm{m}^{-2}\right)$, and $-200 \mathrm{e}\left(-0.28 \mathrm{C} \mathrm{m}^{-2}\right)$ charged nanoparticles for a $0.1 \mathrm{M} \mathrm{CaCl}_{2}$ solution.
TABLE II. Integration number of $\mathrm{Ca}^{2+}$ ions and oxygen atoms of water molecules from the center to the nanoparticle to 3.0 and/or $3.25 \mathrm{~nm}$ in simulations of $\mathrm{CaCl}_{2}$ solutions.

\begin{tabular}{lrrrr}
\hline \hline System & $-25 \mathrm{e}$ & $-50 \mathrm{e}$ & $-100 \mathrm{e}$ & $-200 \mathrm{e}$ \\
\hline $\mathrm{Ca}^{2+}, 0.1 \mathrm{M}$ at $3.0 \mathrm{~nm}$ & 0.9 & 2.8 & 11.4 & 33.6 \\
$\mathrm{Ca}^{2+}, 1 \mathrm{M}$ at $3.0 \mathrm{~nm}$ & 0.3 & 3.3 & 9.9 & 28.1 \\
$\mathrm{Ca}^{2+}, 0.1 \mathrm{M}$ at $3.25 \mathrm{~nm}$ & 4.2 & 14.2 & 39.0 & 88.3 \\
$\mathrm{Ca}^{2+}, 1 \mathrm{M}$ at $3.25 \mathrm{~nm}$ & 14.3 & 24.7 & 53.9 & 104.4 \\
$\mathrm{O}$ water, $0.1 \mathrm{M}$ at $3.0 \mathrm{~nm}$ & 95.8 & 190.9 & 408.3 & 814.4 \\
$\mathrm{O}$ water, $1 \mathrm{M}$ at $3.0 \mathrm{~nm}$ & 66.9 & 141.2 & 311.3 & 670.8 \\
\hline \hline
\end{tabular}

tance as the charged sites of the nanoparticle. This conclusion is also reached from the comparison of the integration numbers of $\mathrm{Ca}^{2}+$ ions until $3.0 \mathrm{~nm}$ with respect to the $\mathrm{Na}^{+}$at the same conditions (Table II). However, this situation is reversed when we compared the integration number of counterions until a distance of $3.25 \mathrm{~nm}$. The number of $\mathrm{Na}^{+}$ions are always less than the number of $\mathrm{Ca}^{2+}$ multiplied per its valence. The only exception corresponds to the case of the lowest charged nanoparticle surrounded by the lowest salt concentration. In this case, a similar value for the accumulated density multiplied by the ion valence is obtained. This result contrasts with the one obtained from simulations using the primitive model with a hard nanoparticle model, in which the accumulated charge profile for divalent ions is, at all distances, greater than the corresponding to the monovalent ions. ${ }^{13}$

The local density of $\mathrm{Ca}^{2+}$ ions in function of the distance to the center of the nanoparticle is shown in Figure 6(a) for a $1 \mathrm{M} \mathrm{CaCl}_{2}$ solution. At this concentration, there are no peaks around $2.8 \mathrm{~nm}$, whereas the density of the peaks around $3.0 \mathrm{~nm}$ increases with the nanoparticle charge. These two different tendencies are counterbalanced and the integration of the number of $\mathrm{Ca}^{2}+$ ions until $3.0 \mathrm{~nm}$ gives similar quantities for both concentrations at each charged nanoparticle (Table II). The maximum difference, around 5-6 counterions, is obtained for the $-200 \mathrm{e}$ charged nanoparticle. With respect to the integration until $3.25 \mathrm{~nm}$, we observe in all cases an important increase of the number of counterions going from $0.1 \mathrm{M} \mathrm{CaCl}_{2}$ solution to $1 \mathrm{M}$ concentration. Thus, the effect of increasing the bulk concentration of the divalent salt is the increase of the quantity of counterions in the external part of the surface as observed also in the simulations of the monovalent salt.

The profile of the accumulated charge with respect to the distance to the center of the nanoparticle for a $0.1 \mathrm{M} \mathrm{CaCl}_{2}$ solution is shown in Figure 5(b). For $-25 \mathrm{e}\left(-0.035 \mathrm{C} \mathrm{m}^{-2}\right)$, $-50 \mathrm{e}\left(-0.07 \mathrm{C} \mathrm{m}^{-2}\right)$, and $-100 \mathrm{e}\left(-0.14 \mathrm{C} \mathrm{m}^{-2}\right)$ charged nanoparticles, a monotonic increase of the accumulated charge up to zero is observed. For the case of the $-200 \mathrm{e}$ $\left(-0.28 \mathrm{C} \mathrm{m}^{-2}\right)$ charged model, a wider maximum is observed around $3.8 \mathrm{~nm}$. Because of the great width and low accumulated charge value of this maximum, these conditions seem to be the point for this system where the overcharging phenomenon starts to appear. In contrast, in the simulations with $1 \mathrm{M} \mathrm{CaCl}_{2}$ solutions (Figure 6(b)), a clear maximum is observed from 3.3 to $3.4 \mathrm{~nm}$ for all discretely charged nanoparticles. This marked maximum indicates that overcharging 

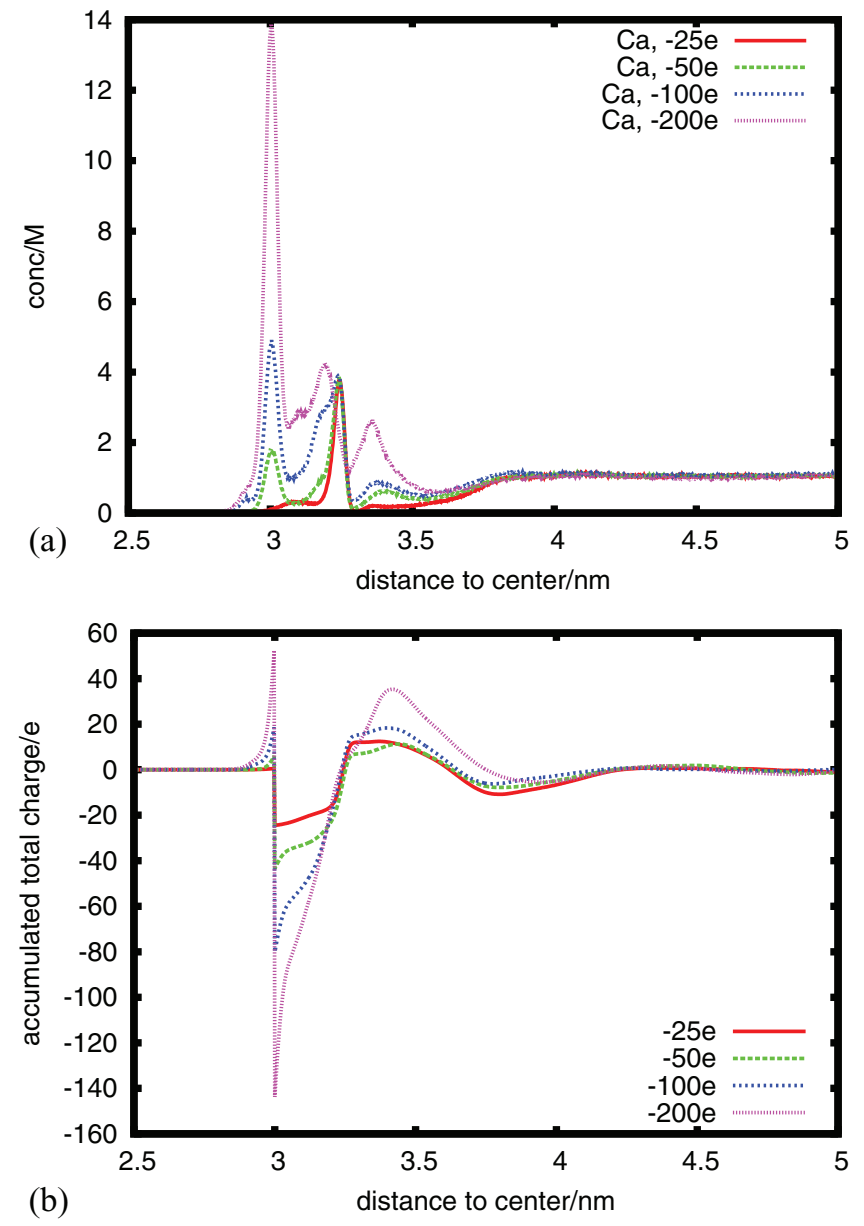

FIG. 6. Density profiles of $\mathrm{Ca}^{2}+$ ions (a) and accumulated charge profiles (b) with respect to the center of the $-25 \mathrm{e}\left(-0.035 \mathrm{C} \mathrm{m}^{-2}\right),-50 \mathrm{e}\left(-0.07 \mathrm{C} \mathrm{m}^{-2}\right)$, $-100 \mathrm{e}\left(-0.14 \mathrm{C} \mathrm{m}^{-2}\right)$, and $-200 \mathrm{e}\left(-0.28 \mathrm{C} \mathrm{m}^{-2}\right)$ charged nanoparticles for a $1 \mathrm{M} \mathrm{CaCl}_{2}$ solution.

exists in all these situations. The highest maximum corresponds to the $-200 \mathrm{e}$ case with an accumulated charge of around $40 \mathrm{e}$ indicating that $20 \mathrm{Ca}^{2}+$ ions more than the required to compensate the charge of the nanoparticle are localized close to its surface.

Figures 7(a) and 7(b) show the distribution of water molecules with respect to the distance to the center of the nanoparticle for both $0.1 \mathrm{M}$ and $1 \mathrm{M} \mathrm{CaCl}_{2}$ concentrations. As observed in the simulations with $\mathrm{NaCl}$, water molecules can internalize into the nanoparticle between the last two layers of sites. The number of internal water molecules increases with the nanoparticle charge. The effect of increasing the bulk salt on the internalization of water is the same as observed for the monovalent salt. A smaller number of water molecules are internalized with the increase of $\mathrm{CaCl}_{2}$ concentration (Table II). In percentage, this reduction is more important for the less charged nanoparticle. The obtained values are $30 \%$, $26 \%, 24 \%$, and $18 \%$ of reduction of water molecules for $-25 \mathrm{e}$ $\left(-0.035 \mathrm{C} \mathrm{m}^{-2}\right),-50 \mathrm{e}\left(-0.07 \mathrm{C} \mathrm{m}^{-2}\right),-100 \mathrm{e}(-0.14 \mathrm{C}$ $\left.\mathrm{m}^{-2}\right)$, and $-200 \mathrm{e}\left(-0.28 \mathrm{C} \mathrm{m}^{-2}\right)$ charged nanoparticles, respectively. Thus, as obtained for the monovalent salt, the increase of the divalent salt concentration does not change the
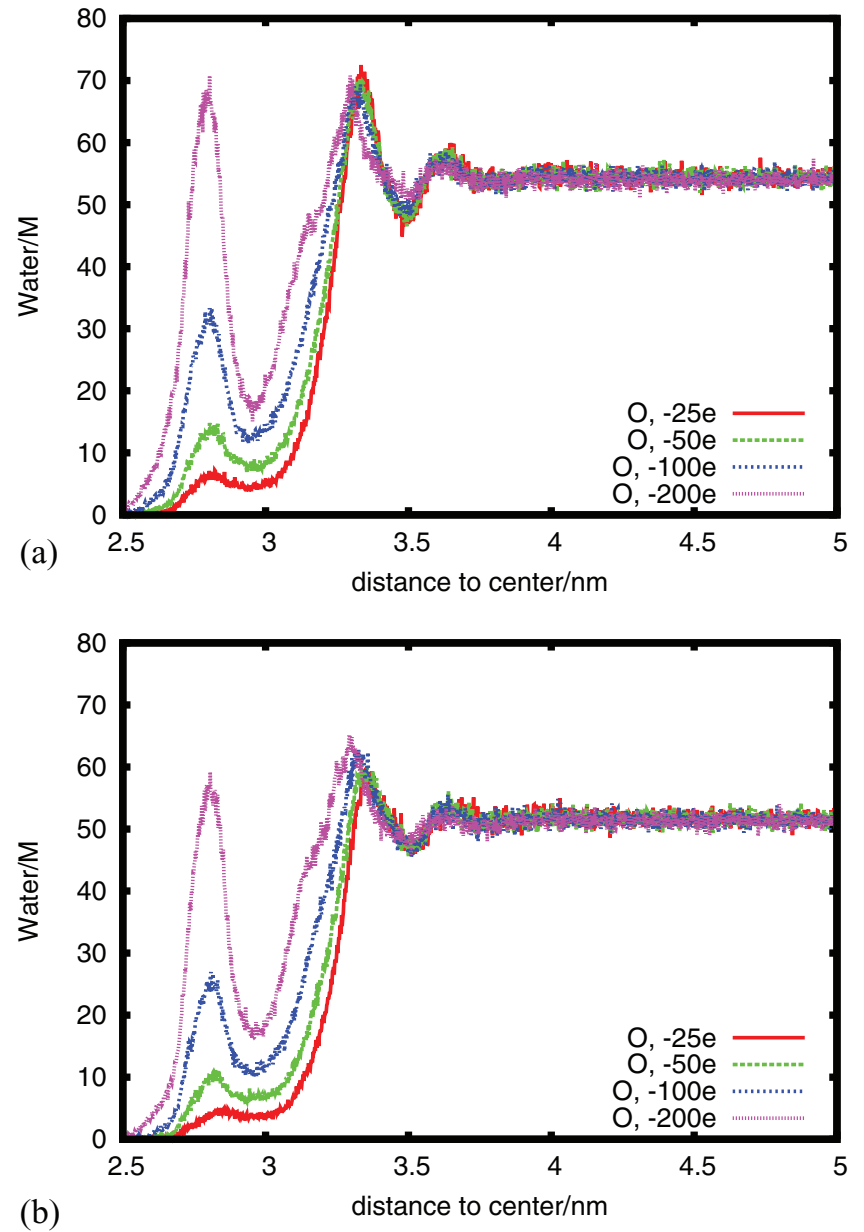

FIG. 7. Density of water molecules with respect to the center of the $-25 \mathrm{e}$ $\left(-0.035 \mathrm{C} \mathrm{m}^{-2}\right),-50 \mathrm{e}\left(-0.07 \mathrm{C} \mathrm{m}^{-2}\right),-100 \mathrm{e}\left(-0.14 \mathrm{C} \mathrm{m}^{-2}\right)$, and $-200 \mathrm{e}$ $\left(-0.28 \mathrm{C} \mathrm{m}^{-2}\right)$ charged nanoparticles for (a) $0.1 \mathrm{M} \mathrm{CaCl}_{2}$ and (b) $1 \mathrm{M} \mathrm{CaCl}_{2}$ solutions.

permeability of the nanoparticle to the penetration of counterions, but reduces the penetration of solvent molecules.

To analyze the different internalization behaviour of $\mathrm{Na}^{+}$ and $\mathrm{Ca}^{2}+$ ions, we computed the number of water molecules in their first solvation shell as a function of the distance of the ion to the nanoparticle center (Figure 8). It can be seen that the coordination number of $\mathrm{Na}^{+}$and $\mathrm{Ca}^{2}+$ ions is constant at long distances from the nanoparticle (with values between 7 and 8 for $\mathrm{Ca}^{2+}$ and between 4 and 5 for $\mathrm{Na}^{+}$) and it diminishes in the proximities of the nanoparticle surface. $\mathrm{Na}^{+}$ions lose about one coordinated water molecule in going from the bulk to the interface (in the 2.8 to $3.2 \mathrm{~nm}$ distance range). At a distance of $2.7 \mathrm{~nm}$, a position where the $\mathrm{Na}^{+}$ion is already internalized, only one water molecule is kept in the solvation shell. In contrast, $\mathrm{Ca}^{2+}$ ions lose about two water molecules in going from the bulk to the interface at a distances 2.9, 3.1, and $3.2 \mathrm{~nm}$. However, because of the greater size of $\mathrm{Ca}^{2}$, at $3.0 \mathrm{~nm}$ (the bottleneck distance to enter in the nanoparticle holes) $\mathrm{Ca}^{2+}$ loses an additional water molecule. In contrast to $\mathrm{Na}^{+}$ions, the $\mathrm{Ca}^{2}+$ ions lose all the coordinated water molecules at the distance of $2.8 \mathrm{~nm}$. Thus, its smaller size allows the $\mathrm{Na}^{+}$ions keeping a greater number of coordinated waters at $2.8 \mathrm{~nm}$ than the $\mathrm{Ca}^{2}{ }^{+}$. This different solvation 


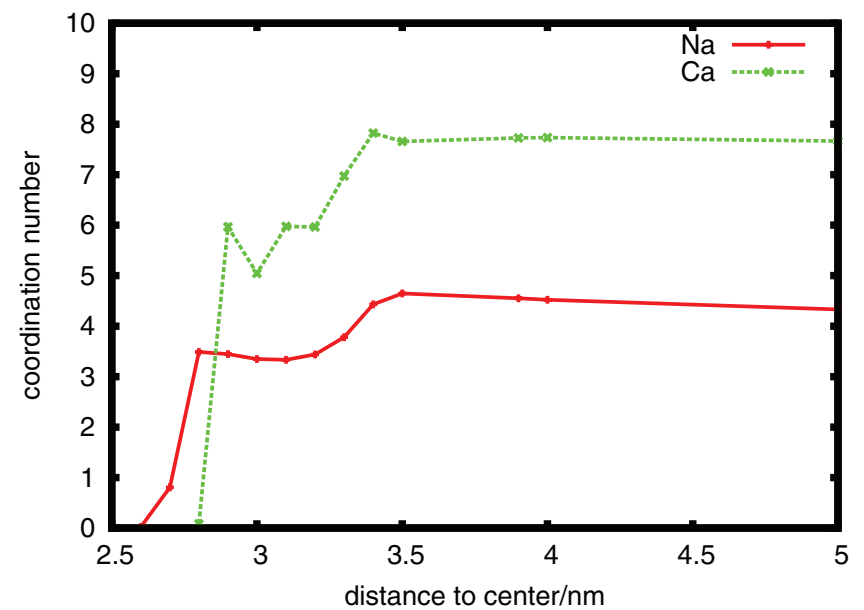

FIG. 8. Representation of the variation of the number of water molecules coordinating $\mathrm{Na}^{+}$or $\mathrm{Ca}^{2}+$ ions as a function of the distance to the nanoparticle center.

number is the reason why the first peak in the density of $\mathrm{Na}^{+}$ that appears at $2.8 \mathrm{~nm}$ is missing in the $\mathrm{Ca}^{2}+$ profiles.

\section{Effect of discretization of the surface charge}

To study the effect of discretization of the surface charge of the nanoparticle, a new set of simulations were performed distributing the surface charge over all the 370 surface sites. For the nanoparticle with a charge of $-100 \mathrm{e}$, all the sites were assigned a fractional charge of $-100 / 370 \mathrm{e}$ maintaining the same surface charge density of $-0.14 \mathrm{C} \mathrm{m}^{-2}$. In Figure 9(a), it can be seen that for $0.1 \mathrm{M}$ and $1 \mathrm{M} \mathrm{CaCl}_{2}$ concentrations, $\mathrm{Ca}^{2}+$ ions are distributed in a different way depending on if the -100 e charge is distributed randomly over 100 out of 370 surface sites, or if all the surface sites are charged with the $-100 / 370$ e value. In the simulations using the uniform charge distribution, the density profile of $\mathrm{Ca}^{2}+$ ions in function of the distance to the center of the nanoparticle shows only one maximum located at longer distances from the nanoparticle surface sites. At both concentrations, $\mathrm{Ca}^{2}+$ ions are accumulated at longer distances from the surface than in the case of simulations using the discrete distribution of the nanoparticle charge. Thus, the selected model for the distribution of the nanoparticle charge affects the counterion distribution and its degree of permeability. This effect is not observed when a mean field theory that considers a uniform charge density for the nanoparticle surface is used.

Important differences are also observed in the profiles of the accumulated charge between simulations with uniform and discrete charge distribution in the nanoparticle surface (Figure 9(b)). For the case of uniform distribution, the profiles are shifted around $0.4 \mathrm{~nm}$ to longer distances. For the system with a $1 \mathrm{M} \mathrm{CaCl}_{2}$ concentration, the overcharging phenomenon is observed for both distribution models but the peak of the profile is also shifted to longer distances from the nanoparticle surface when the charge distribution is uniform.

The comparison of the distribution of water molecules obtained for simulations with $0.1 \mathrm{M} \mathrm{CaCl}_{2}$ and $1 \mathrm{M} \mathrm{CaCl}_{2}$ solutions using the discrete charge model and the uniform
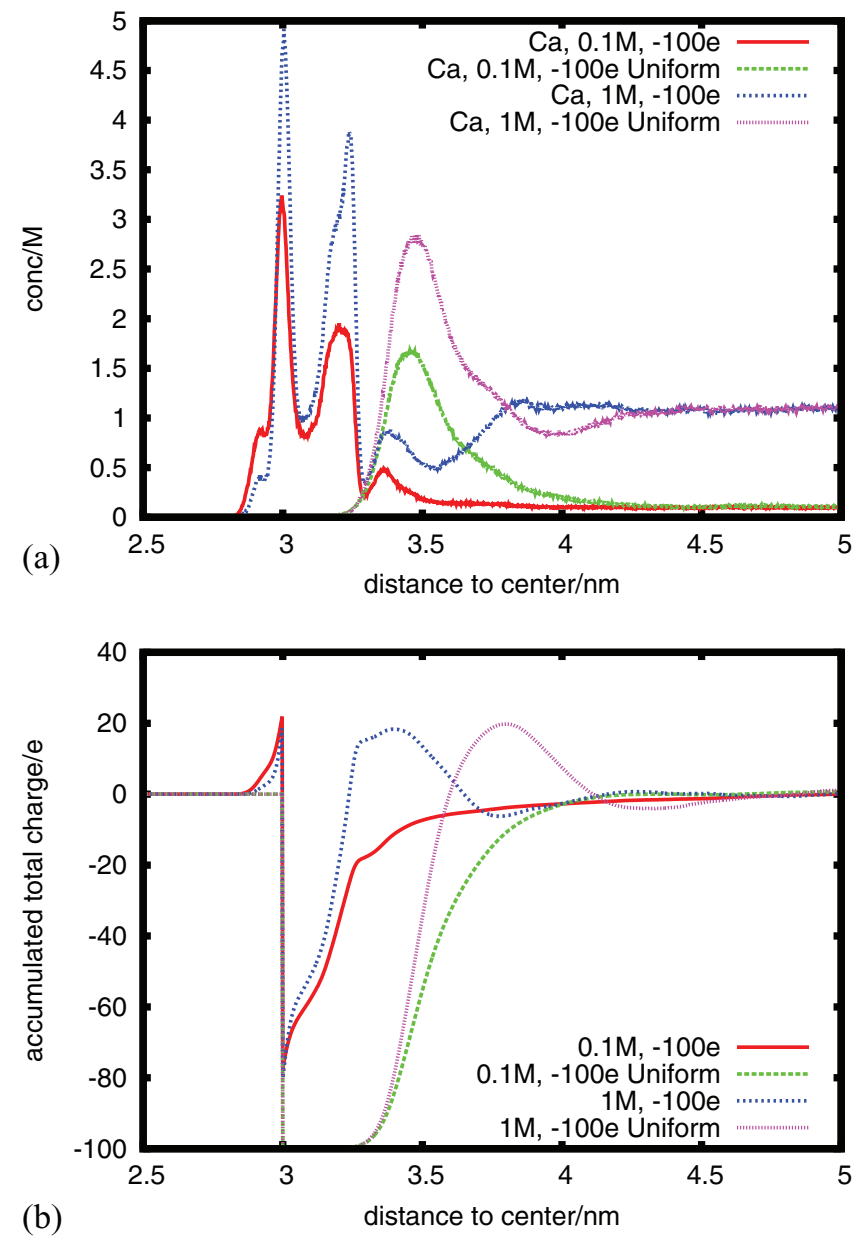

FIG. 9. Density profiles of $\mathrm{Ca}^{2}+$ ions with respect to the distance to the center of the $-0.14 \mathrm{C} \mathrm{m}^{-2}$ uniformly and non-uniformly charged nanoparticle for $0.1 \mathrm{M} \mathrm{CaCl}_{2}$ and $1 \mathrm{M} \mathrm{CaCl}_{2}$ solutions (a) and their corresponding accumulated charge profiles (b).

charge model of the $-0.14 \mathrm{C} \mathrm{m}^{-2}$ nanoparticle can be seen in Figure 10. In the uniform charge distribution, the density of water molecules below $3.0 \mathrm{~nm}$ is lower than the observed for the simulation using a discrete random distribution of the nanoparticle charge, and no maximum is observed for the

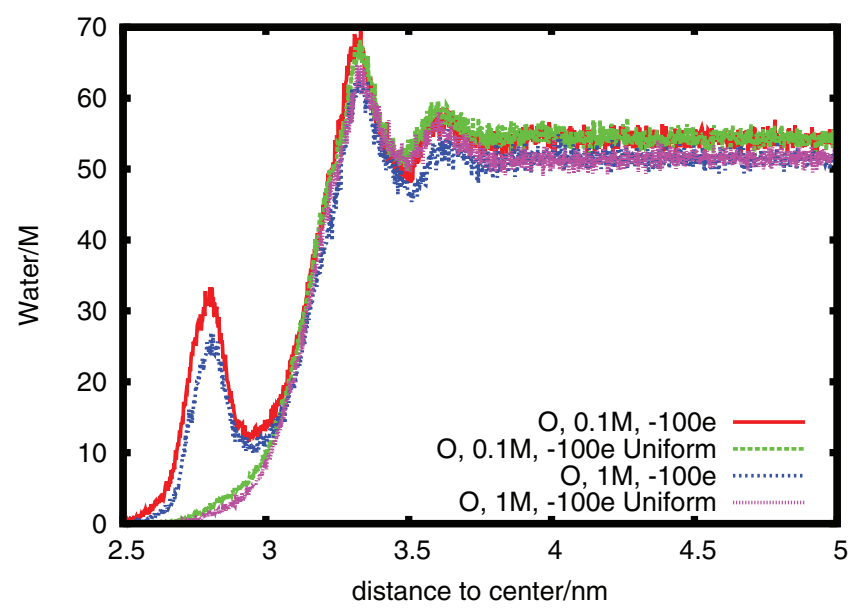

FIG. 10. Density of water molecules with respect to the distance to the center of the $-0.14 \mathrm{C} \mathrm{m}^{-2}$ uniformly and non-uniformly charged nanoparticle for $0.1 \mathrm{M} \mathrm{CaCl}_{2}$ and $1 \mathrm{M} \mathrm{CaCl}_{2}$ solutions. 
water density inside the nanoparticle. As with the uniform charge distribution, a smaller charge value is assigned to the surface sites, hydrogen bonds are too much weak to stabilise water molecules inside the nanoparticle. Thus, the procedure used to distribute the nanoparticle surface charge has important effects on the distribution of both counterions and water molecules.

\section{CONCLUSIONS}

The EDL of a spherical charged soft nanoparticle in different salt solutions was studied by molecular dynamics simulations using a soft colloidal model. We varied the charge of the nanoparticle, the valence of the counterions, and the bulk concentration of the added salt.

We obtained that $\mathrm{Na}^{+}$and $\mathrm{Ca}^{2}+$ ions are able to internalize into the nanoparticle. Monovalent ions are more accumulated inside the nanoparticle surface whereas divalent ions are more accumulated just in the plane of the nanoparticle surface sites. The increase of bulk concentration of $\mathrm{NaCl}$ or $\mathrm{CaCl}_{2}$ reduces the internalization of water molecules whereas the counterion permeability remains nearly constant.

The different behaviour of $\mathrm{Na}^{+}$and $\mathrm{Ca}^{2}+$ ions in the surface of the nanoparticle is related to the ability to keep a significant number of coordinated water molecules. $\mathrm{Na}^{+}$ions, being smaller than $\mathrm{Ca}^{2}+$ ions, are able to keep a significant number of coordinated water molecules and to internalize 0.1 nm more inside than $\mathrm{Ca}^{2}+$ ions.

The way that the charge is distributed over the nanoparticle surface yields very different profiles for counterion and water molecules. In particular, using a uniform charge distribution the permeability of the nanoparticle to counterions and water molecules is significantly reduced.

\section{ACKNOWLEDGMENTS}

The authors gratefully acknowledge support of this research by the Spanish Ministry of Science and Technology (Project No. CTM2009-14612) and by the Generalitat de Catalunya (Grant Nos. 2009SGR465 and XRefQTC). M.N. thanks the HPC-Europa2 project (Project No. 228398) for financial and technical support, as well as the European Commission Capacities Area-Research Infrastructures Initiative. I.P. thanks the Juan de la Cierva Program of the Spanish Ministry of Science.

${ }^{1}$ T. Tadros, Adv. Colloid Interface Sci. 46, 1 (1993).

${ }^{2}$ M. Ballauff, Prog. Polym. Sci. 32, 1135 (2007).

${ }^{3}$ M. Ballauff, Curr. Opin. Colloid Interface Sci. 11, 316 (2006).

${ }^{4}$ A. Poater, A. G. Saliner, R. Carbó-Dorca, J. Poater, M. Solà, L. Cavallo, and A. P. Worth, J. Comput. Chem. 30, 275 (2009).

${ }^{5}$ P. Pincus, Macromolecules 24, 2912 (1991).

${ }^{6}$ X. Guo and M. Ballauff, Phys. Rev. E 64, 051406 (2001).

${ }^{7}$ K. Kostarelos, Adv. Colloid Interface Sci. 106, 147 (2003).

${ }^{8}$ M. Borkovec, B. Jönsson, and G. J. M. Koper, Surface and Colloid Science, edited by E. Matijevic (Kluwer Academic, New York, 2001), Vol. 16, Chap. 2.

${ }^{9}$ M. Quesada-Pérez, E. González-Tovar, A. Martín-Molina, M. LozadaCassou, and R. Hidalgo-Álvarez, Chem. Phys. Chem. 4, 234 (2003).

${ }^{10}$ S. Madurga, A. Martín-Molina, E. Vilaseca, F. Mas, and M. Quesada-Pérez, J. Chem. Phys. 126, 234703 (2007).

${ }^{11}$ S. Madurga, C. Rey-Castro, I. Pastor, E. Vilaseca, C. David, J. L. Garcés, J. Puy, and F. Mas, J. Chem. Phys. 135, 184103 (2011).

${ }^{12}$ L. Degrève, M. Lozada-Cassou, E. Sánchez, and E. González-Tovar, J. Chem. Phys. 98, 8905 (1993).

${ }^{13}$ R. Messina, Phys. A 308, 59 (2002).

${ }^{14}$ S. Ravindran and J. Wu, Condens. Matter Phys. 8, 377 (2005).

${ }^{15}$ G. I. Guerrero, E. González-Tovar, and M. Chávez-Páez, Phys. Rev. E 80, 021501 (2009).

${ }^{16}$ R. Ni, D. Cao, and W. Wang, J. Phys. Chem. B 110, 26232 (2006).

${ }^{17}$ C. N. Patra, J. Phys. Chem. B 113, 13980 (2009).

${ }^{18}$ B. Modak, C. N. Patra, S. K. Ghosh, and J. Vijayasundar, Mol. Phys. 109, 639 (2011).

${ }^{19}$ A. R. Rakitin and G. R. Pack, Colloid Surf., A 218, 265 (2003).

${ }^{20}$ A. R. Rakitin and G. R. Pack, J. Phys. Chem. B 108, 2712 (2004).

${ }^{21}$ O. V. Semashko, S. V. Burov, and E. N. Brodskaya, Colloid J. 71, 846 (2009).

${ }^{22}$ E. Brodskaya, J. Phys. Chem. B 116, 5795 (2012).

${ }^{23}$ S. Madurga, J. L. Garcés, E. Companys, C. Rey-Castro, J. Salvador, J. Galceran, E. Vilaseca, J. Puy, and F. Mas, Theor. Chem. Acc. 123, 127 (2009).

${ }^{24}$ B. Hess, C. Kutzner, D. van der Spoel, and E. Lindahl, J. Chem. Theory Comput. 4, 435 (2008).

${ }^{25}$ D. van der Spoel, E. Lindahl, B. Hess, G. Groenhof, E. Mark, and H. J. C. Berendsen, J. Comp. Chem. 26, 1701 (2005).

${ }^{26}$ E. Lindahl, B. Hess, and D. van der Spoel, J. Mol. Model. 7, 306 (2001).

${ }^{27}$ H. J. C. Berendsen, D. van der Spoel, and R. van Drunen, Comput. Phys. Commun. 91, 43 (1995).

${ }^{28}$ U. Essman, L. Perela, M. L. Berkowitz, T. Darden, H. Lee, and L. G. Perdersen, J. Chem. Phys. 103, 8577 (1995).

${ }^{29}$ G. Bussi, D. Donadio, and M. Parrinello, J. Chem. Phys. 126, 014101 (2007).

${ }^{30}$ S. Miyamoto and P. A. Kollman, J. Comput. Chem. 13, 952 (1992). 